\title{
1 Introduction: Disasters and History
}

\subsection{The Key Themes of the Book}

This monograph provides an overview of research into disasters from a historical perspective, making two new contributions. First, it introduces the field of 'disaster studies' to history, showing how we can use history to better understand how societies deal with shocks and hazards and their potentially disastrous outcomes. Despite growing recognition of the importance of historical depth by scholars investigating disasters, the temporal dimensions of disasters have been underexploited up to now. Moreover, the historical record sometimes enables us to make a longterm reconstruction of the social, economic, and cultural effects of hazards and shocks that is simply not possible in contemporary disaster studies material. We can therefore use 'the past' as a laboratory to test hypotheses of relevance to the present in a careful way. History lends itself to this end because of the opportunity it offers to identify distinct and divergent social and environmental patterns and trajectories. We can compare the drivers and constraints of societal responses with shocks spatially and chronologically, and therefore enrich our understanding of responses to stress today.

Second, we introduce historians to the topic of disasters and the field of disaster studies, and explicitly show the relevance of studying past disasters to better understand the social, economic, and political functioning of past societies. Disasters often reveal features of society which in normal situations remain hidden from the view of the historian, for example, the entrenched vulnerability of particular groups within society or the manifestation of uneven power relations. People sometimes behaved in different ways during periods of pressure when compared with 'normal' times. Studying disasters thus allows historians to bridge the gap between 'event' and 'structure.' In particular, we show, through the lens of history and disasters, how the past can be used to carry out systematic spatiotemporal 
comparison and to empirically test hypotheses developed in the social and natural sciences. In this sense, the book looks to enrich approaches in the contemporary study of disasters, but also approaches and methodologies employed in the discipline of history.

The shocks and hazards on which this book concentrates are biophysical ones, including seismic activity, droughts, high water tables, and epidemics. Political and economic crises, war, and other human-made shocks may figure in the text, not per se, but as factors sharpening the effects of natural hazards or interacting with them. The broad objective of the book is to show how history can be used to demonstrate how these biophysical shocks and hazards, sometimes leading to disasters, push societies in different directions - creating a diversity of possible social and economic outcomes. Further, in this book we aim to identify the patterns and mechanisms involved in producing these outcomes.

This diversity of outcome is produced in three phases (see Figure 1.1). First, we show that the nature of the initial shocks to societies was often very different - some killing people but leaving capital untouched (such as the Black Death), others destroying capital and infrastructure but

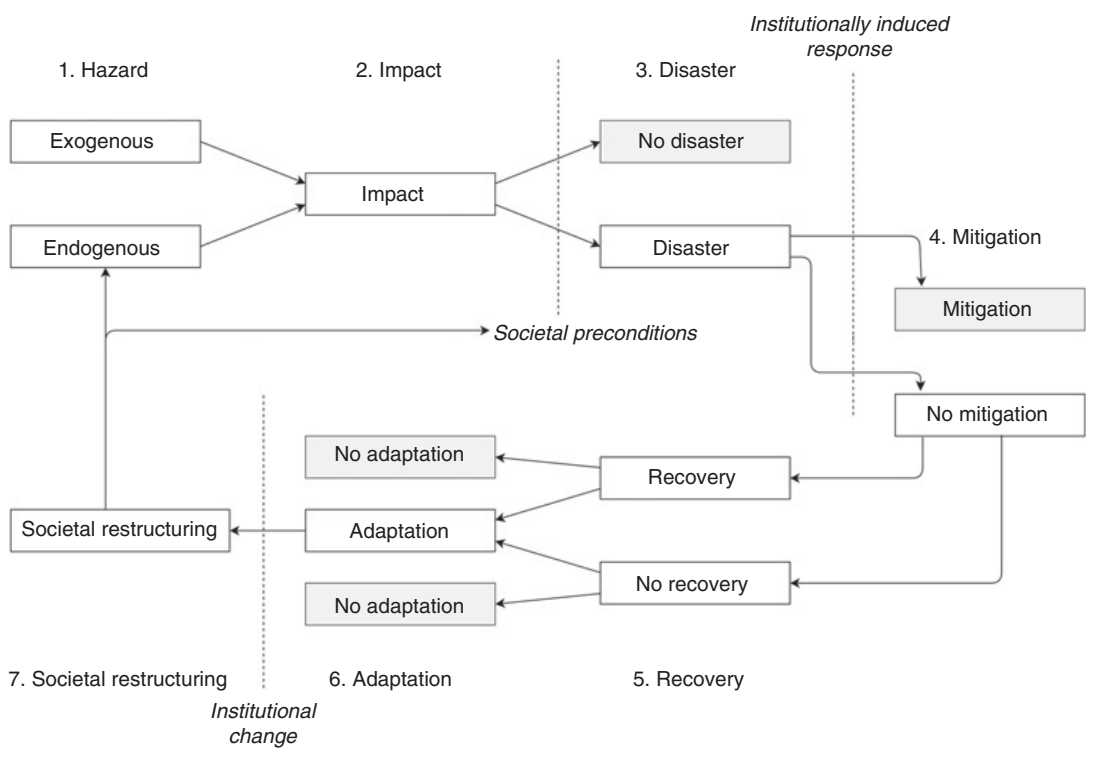

Figure 1.1 Diversity of outcomes through hazards, disasters, and adaptation, illustrating the framework used throughout this book. Drawn by Jasmin Palamar, Utrecht University. 
inflicting only modest casualties (such as most floods), and others destroying both at the same time (such as the most severe earthquakes, or epidemics occurring together with military activity). Put simply, the effects that different shocks had on production factors and the demands on infrastructure were not always the same. Even for the same type of shock there was great diversity: not all epidemics, for example, had universal features. Instead, they exhibited differences in epidemiologic characteristics on the grounds of severity, pervasiveness, longevity, seasonality, selectivity, and so on.

Second, we show that even when hazards and shocks had similar features, their outcomes often varied as a result of interacting with very different social, economic, political, and cultural settings, whereby dissimilar levels of pre-existing vulnerability acted as a 'filter' for the shock itself. Of course, famines and floods posed challenges very different from those of earthquakes or volcanic eruptions, but even societies interacting with the very same hazard were not always impacted in an identical way, nor did they always move in the same direction. Pre-existing vulnerability, a lack of preparedness, or ill-functioning institutions could turn a modest shock into a true disaster, while well-prepared and less vulnerable societies could withstand much bigger hazards and threats and even prevent them from turning into a disaster. Numerous kinds of institutional responses were formed at a variety of scales - some stronger on a supralevel through the state or long-distance markets, some stronger on a meso-level through collectives - such as guilds, community associations, organizations for the management of common-pool resources, insurance systems, and so on - and others stronger on a micro-level as households, families, and neighbors became the most dominant form of welfare, assistance. and protection. The arrangement and combination of these different scales of response helped create a diversity of outcomes.

Third, we show that even two different societies facing the same hazard with the same kinds of institutional responses still did not always produce the same post-hazard trajectories. As a major element to the book, we aim to demonstrate that although many historical societies shared a number of ways of dealing with the same shocks and hazards on the surface, for example in the form of poor relief institutions, flood management infrastructure, or commonly managed resources, the outcomes could still be quite different. In order to explain these differences, we look at the social actors behind the institutional responses themselves, showing that rather than being 'rational' responses offering the greatest amount of protection or welfare by way of institutional adaptation, these responses were the products of different social actors with goals not always equivalent to the 'common good.' Accordingly, we illustrate how shocks and hazards, and 
the disasters that ensued, could have very diverse consequences and outcomes, not only between societies, but also within the same societies, between social groups, and across wealth, ethnic, and gender lines, and we try to find patterns and mechanisms in order to better understand these diverse outcomes.

As well as focusing on diversity of outcomes, this book also addresses a number of key themes in disasters and history. An important one is that of anticipation, preparedness and memory. Hazards, and the disasters sometimes produced, are often not unexpected. Every region continuously had to cope with recurring sets of hazards and threats. Coastal zones, for instance, were constantly confronted by the threat of storm surges and floods, and therefore often formed a 'region of risk.' ${ }^{1}$ This book addresses past societies' levels of preparedness, anticipation, and memory of hazards which emerge over the long term. Some societies were not only aware of the environmental threats but anticipated hazards and built a society that could cope with hazard reoccurrence. ${ }^{2}$ Others, however, did not or could not anticipate and were therefore more vulnerable to unexpected environmental shocks. By looking into different cultural or social barriers, institutional flaws, and political constellations, we explain why certain societies were able to develop 'subcultures' of coping and introduced successful protection measures, while in others an effective response and level of preparedness was lacking. For example, some historians and historical geographers have suggested that 'cultural memory' of past hazards and disasters may have been important, helping initiate technological and infrastructure-based reorganization. Yet at the same time, memories of past events were sometimes manipulated by authorities - in the case of plague, for example, to act as a cautionary warning to citizens on how to behave. ${ }^{3}$ Furthermore, mere knowledge of and experience with previous or repeat occurrences of hazards was not enough to stimulate adaptive practice in every case. That is to say, these responses were not always rational and effective reactions to protect the common good, but were sometimes used to promote the interests of select groups within society. Barriers could emerge to prevent successful adaptation regardless of knowledge and experience: in Southern Nyasaland (Malawi) after the 1949 famine, for example, peasants were largely prevented from using traditional ecological knowledge such as switching from maize to the more drought-resistant sorghum and from intensification of riverbank cultivation, by government policies that

\footnotetext{
${ }^{1}$ Bankoff, 'The "English Lowlands"'; Mauelshagen, 'Flood Disasters and Political Culture.'

${ }^{2}$ Bankoff, 'Cultures of Disaster.' $\quad{ }^{3}$ Carmichael, 'The Last Past Plague,' 159.
} 
prioritized the development of colonial cash crops at the expense of reducing sensitivity to drought. ${ }^{4}$ Accordingly, coping mechanisms cannot be understood in isolation, but must be viewed in the wider context of societal organization and the associated institutional framework: that is, in relation to institutions not necessarily geared towards coping with hazards but serving very different goals.

Another key theme is that of disaster impacts. What are these diverse outcomes that we are able to reconstruct? Mortality is an obvious variable, ${ }^{5}$ even though for some historical disasters precise data on the number and social profile of victims are lacking. Recent literature has shown how epidemics had different scales of severity and territorial reach not just between outbreaks, but also for the same outbreak across localities. ${ }^{6}$ Likewise, it has been shown that neither periods of extreme weather nor periods of high prices in food products inevitably led to the same mortality effect. ${ }^{7}$ Recent work on flooding has shown considerable regional differences in the disruption of livelihoods, the numbers of casualties produced, and the socio-economic profile of the victims. ${ }^{8}$

Mortality is not necessarily the optimal variable for all types of disasters, however. Some disasters did not cause high mortality but were disastrous on a different level. Floods or erosion could have devastating effects without killing a single person. For example, virtually nobody was killed 'directly' because of the sand storms during the American Dust Bowl in the 1930s. Nevertheless, this development has been labeled "one of the three worst ecological disasters in history," " because of the loss of productive land that crippled the Midwestern economy indefinitely, with recent research showing significant medium- and long-term effects for human capital formation and for later-life health and income. ${ }^{10}$ As a result, different variables could be applicable according to the type of disaster, such as capital destruction (in the form of land, labor, or financial capital), falling yields, or erosion of societal stability potentially leading to scapegoating or trauma. For historical disasters, capital destruction and changing yields or land use can be traced, as they left at least some marks in the written documentary sources, even if this is not always methodologically straightforward. A more complicated and less

\footnotetext{
${ }^{4}$ Vaughan, 'Famine Analysis.' $\quad{ }^{5}$ Sen, 'Mortality.'

${ }^{6}$ Alfani, 'Plague in Seventeenth-Century Europe'; Curtis, 'Was Plague an Exclusively Urban Phenomenon?'

${ }^{7}$ Curtis \& Dijkman, 'The Escape from Famine,' 235-236; Ó Gráda \& Chevet, 'Famine and Market,' 714, 728 .

8 Rheinheimer, 'Mythos Sturmflut'; Elliott \& Pais, 'Race, Class, and Hurricane Katrina'; Soens, 'Resilient Societies.'

${ }_{9}^{9}$ Quote from Borgström, World Food Resources, via Worster, Dust Bowl, 4.

${ }^{10}$ Arthi, "The Dust Was Long in Settling."
} 
objective measure is whether a society experienced a societal shift out of its 'stability domain.' This is derived from the field of environmental studies, where a disaster is measured by the magnitude of disturbance that a system can absorb before it changes from one stability domain or ecosystem into another stable domain. ${ }^{11}$ It could be that these forms of ecological resilience can be used for societies as well. ${ }^{12}$ A hazard or shock could be labeled a disaster when a society is pushed out of its former stability domain into a new one. Returning to the American Dust Bowl, this is illustrated by the permanent shift that some regions made from being grain-producing regions towards cattle breeding in the places where the loss of productive soil was most severe.

Shocks and hazards could also stimulate different levels of social unrest. Although a clichéd view used to be that epidemics inevitably pushed all societies into disorder and disarray, perhaps even creating scapegoats, informed by a Foucauldian narrative of top-down repression, more recent work has tended to show oppositional tendencies too, as epidemics became forums for welfare reform, encouraged community cohesion, and provided a vehicle for those at the bottom of society to autonomously vent their frustrations and concerns towards those at the top. ${ }^{13}$ Similarly, during periods of famine, it used to be seen as inevitable that the kinds of pressure generated thereby would break the bonds of society, leading to heightened levels of criminality such as thievery and violence, and yet other works in more recent years have shown how communal bonds of trust could continue and be strengthened even in some of the worst famines. ${ }^{14}$

Over the long term, we also find diversity in economic and demographic outcomes. Some of these were aggregate outcomes such as differences in overall extent and speed of population recovery after a disaster. Demographic development after the Black Death was not the same in the Low Countries as it was in England, Spain, or Egypt ${ }^{15}$ for example, and differed on a regional level too within these countries. ${ }^{16}$ Differences were even seen on a city-by-city level: post-epidemic migration allowed some cities to recover within a matter of years, even exceeding previous populations, while others nearby saw complete contractions. ${ }^{17}$ We look at how these differences were established through the various 'tools' for

${ }^{11}$ Gunderson, 'Ecological Resilience,' 427. ${ }^{12}$ Adger, 'Social Vulnerability.'

13 Cohn, Epidemics; Curtis, 'Preserving the Ordinary.'

${ }^{14}$ Slavin, 'Market Failure'; Vanhaute \& Lambrecht, 'Famine'; van Onacker, 'Social Vulnerability.'

${ }^{15}$ Van Bavel \& van Zanden, 'The Jump-Start'; Malanima, Pre-modern European Economy; Borsch, The Black Death.

${ }^{16}$ Lewis, 'Disaster Recovery,' 792-793; van Bavel, 'People and Land,' 6-8.

${ }^{17}$ For post-Black Death Tuscany: Herlihy \& Klapisch-Zuber, Les Toscans et leurs familles. 
demographic recovery that societies had at their disposal - nuptiality, fertility, migration, welfare safety-nets, and grip over economic resources and opportunities.

Many of the long-term differences in economic outcomes we discuss, however, were redistributive. Hazards and shocks helped redistribute economic resources between social groups, therefore making societies more or less unequal. Indeed, scholars such as Branko Milanovic have suggested that "epidemics and wars alone can explain most of the swings in [pre-modern] inequality," while Walter Scheidel believes that the only time socio-economic inequalities leveled themselves out throughout history was during episodes of mass violence, destruction, or mortality. ${ }^{18} \mathrm{By}$ its very nature, this kind of redistribution creates diverse outcomes giving to some while taking away from others within the same society but the level of post-shock redistribution also differed from context to context. In some cases, a lasting equitable effect was seen - the Black Death and recurring plagues in Northern and Central Italy, for example, decreasing inequality for the next century or more, whereas yet other epidemics, such as the 1629-30 outbreak in Northern Italy, had only very brief and short-run equitable effects that quickly disappeared or were negated by certain institutions being employed to maintain the 'status quo'. ${ }^{19}$ In contrast to the 'leveling hypothesis,' other shocks, however, pushed redistributive outcomes in the opposite direction, as certain groups 'instrumentalized' the hazard to their advantage - elites buffering destructive shocks to capital goods in times of floods or hoarding and speculating in times of famine.

Hazards and shocks also helped redistribute resources and opportunities between social groups in the same community. Disasters did not mean the same things for the very young or the very old as they did for working-age adults, or for 'native' inhabitants when compared with the experiences of 'recent' migrants, or for rural dwellers compared with those of the cities. Studies on contemporary disasters tend to emphasize, for example, how women are more susceptible than men to various negative outcomes from disasters - and yet historical work on the subject tends to find differential trajectories, dependent on shock and context. A long debate has ensued over the role of the Black Death in improving women's economic fortunes, ${ }^{20}$ and yet it is clear that post-plague opportunities for women differed between regions, if we are to use indicators such as access to property, participation in economic roles outside the household, access to the marriage market, and access to care and

${ }_{18}^{18}$ Milanovic, Global Inequality, 62, 69; Scheidel, The Great Leveler, passim.

${ }^{19}$ See Section 5.3.2. $\quad{ }^{20}$ Rigby, 'Gendering the Black Death.' See Section 5.3.2. 
support. ${ }^{21}$ The same holds for famines. While development economics tends to assert negative aspects for women emanating out of intrahousehold hierarchies dictating access to food or potential for abandonment, pre-modern famine history tends to show more diversity in outcomes - in some cases women experiencing a 'female mortality advantage' vis-à-vis men, or benefiting from their status as creditors with surplus capital or their control over food production, or reaping the benefits of poor relief systems structurally set up for women over men.

In discussing these themes, the book will not be comprehensive in its spatial coverage. Unfortunately, many parts of the globe can hardly be discussed because of the lack of sources or relevant studies. Things are changing for the better, however, with a growing number of studies appearing on the Caribbean, sub-Saharan Africa, and China, for instance. We hope this book will constitute an invitation to scholars working there. This will also enable us to see to what extent the concepts, definitions, and mechanisms presented in this book also apply to other parts of the globe. To be sure, in choosing cases to be discussed, this book does not attempt to be exhaustive. Rather, we feel that touching briefly on a very large number of cases could lead to superficiality and not be in line with one of the core arguments of the book, that is, that hazards and disasters can be understood and explained only by placing them in their social, economic, political, and cultural context. Therefore, we opted to somewhat limit the number of examples to be mentioned and also chose some well-investigated cases to return to throughout the book. Most notably, these cases are the Black Death of 1348 in Europe and the Middle East, the North Sea floods of the late-medieval and earlymodern period, the Lisbon earthquake of 1755, the American Dust Bowl of the 1930s, the sub-Saharan Africa famines of the twentieth century, and the recent earthquake and tsunami in Japan leading to the Fukushima disaster. These cases relate to different types of hazards and offer different time scales (event versus long-run process), and they are relatively well documented and investigated, thus enabling us to highlight the various aspects of each disaster and its wider context.

This book does not limit itself to the modern period, as it takes a longterm perspective and tries to employ the whole of the historical record. Not all periods can be equally rigorously discussed, since there are limitations in terms of the sources and works available, but more attention than often is the case will be paid to the pre-industrial period. This reflects in part the academic background of the authors, but also the fact that this period knew a wide diversity of social, economic, cultural, and political

${ }^{21}$ See Section 6.1.1. 
constellations, often found in close proximity to each other, and thus offers a very rich testing ground replete with opportunities to test ideas and hypotheses and find contrasting experiences that allow us to perform a comparative analysis. ${ }^{22}$ Moreover, despite acknowledging that the Industrial Revolution brought momentous changes, we do not consider it to have formed a fundamental rift making the mechanisms at play in the pre-industrial period fundamentally different and therefore useless for understanding the challenges we are facing now; rather, many of the underlying mechanisms are essentially similar.

Linking up with this, the book explicitly inquires whether the present can be regarded as an 'Age of Disaster.' Higher vulnerability to disasters is often seen as one of the fundamental characteristics of the Anthropocene, the new geological epoch in which humanity influences the basic conditions of the planetary ecosystem directly. ${ }^{23}$ In the Anthropocene, humans are co-producing nature - just as nature co-produces humans - but at the same time humans have to abandon the ambition to control nature, which had been one of the fundamental premises of 'modernity.'24 The Enlightenment and the Industrial Revolution 'modernized' the disaster experience, as disasters were deemed to be both produced by the technological endeavors of men and controlled through technology. Since the late twentieth century, however, it has been argued by some scholars ${ }^{25}$ that control is no longer possible, but risk reduction and adaptation are more crucial than ever, since the extreme events are there, we do not control them, and we cannot escape them.

While the scale and intensity of resource exploitation and technological transformation of the Earth undoubtedly accelerated hugely from the Industrial Revolution onwards, and became even more articulated after World War II, this book nevertheless questions whether pre-modern disasters were indeed very different from 'modern' or 'Anthropocentric' ones. At least they are not different in a fundamental way. First, modern advances did not free us from the risk of disaster. Seen from a long-term world-historical perspective, one could say that "every gain in precision in the coordination of human activity and every heightening of efficiency in production were matched by a new vulnerability to breakdown."26 Second, and even more clearly, the social, political, cultural, and economic settings of societies, and the coordination systems they used a main cause of the divergences in the effects of hazards and disasters

\footnotetext{
${ }^{22}$ Van Bavel \& Curtis, 'Better Understanding Disasters.'

23 Ebert, 'The Age of Catastrophe'.

${ }^{24}$ Chakrabarty, 'The Climate of History.' See Section 7.1.

25 Beck, Lash \& Wynne, Risk Society.

${ }^{26}$ McNeill, The Global Condition, 148; Mauelshagen, 'Defining Catastrophes.'
} 
we highlight throughout the book - do not show a linear progression throughout history. Systems of competitive markets, and their dominance, for instance, can rise and decline, without an inevitable march forward to modernity. ${ }^{27}$ This book thus seeks to replace a linear processional narrative on the modernization of disasters with a more analytical approach that focuses on continuities, disruption, and change in their production, interpretation, and (technological) control. In so doing, we question, for instance, the importance of technology in the production of and resilience to disasters long before the Industrial Revolution, and show the profound regional and social divergences in vulnerability and resilience characterizing 'traditional,' 'modern,' and 'Anthropocenic' societies.

The present experiences show that it is relevant, perhaps even more than ever, to use the historical record to increase our understanding of disasters. Societies all over the globe are confronted with rising water tables and ensuing floods, severe drought, or epidemics, including the COVID-19 pandemic. While the medium- and long-term consequences of these recent disasters will not be known to us for some time, we feel that the concepts, frameworks, and angles of analysis discussed in this book exploring the links between disasters and historical development, and the insights offered by historical analysis, may be fruitfully applied by other future scholars who will want to focus more explicitly on the fallout of present disasters. At the very least, the COVID-19 pandemic shows again how both over-emphasis on 'inevitable' mechanistic frameworks and processional narratives about progress and technology are unfounded and obscure the real effects on people, more particularly the different effects on different groups of people. This requires a better, deeper understanding of the causes of resilience and vulnerability of societies in the face of natural hazards, to which this book, with analysis based on the historical record, hopes to contribute.

\subsection{Disaster Studies and Disaster History: Connected Fields?}

The rise of interest in hazards and disasters as objects of scientific analysis is closely intertwined with the specifics of the Cold War period, when the US government and army became increasingly interested in how the American population would react if a (nuclear) attack occurred. In the 1950s the first research on how people reacted under extreme circumstances, where disasters such as fires, cyclones, and earthquakes were seen as a proxy for war, was conducted mainly by sociologists, looking at

${ }^{27}$ See for markets: van Bavel, The Invisible Hand? 
the social effects of disasters. This continued in the 1960s when the Disaster Research Center (DRC) was founded by three disaster sociologists: Quarantelli, Dynes, and Haas. ${ }^{28}$ At the same time, geographical interest in 'natural hazards' sparked, with a focus on building and land development. ${ }^{29}$ Gilbert White's ground-breaking work on floodplain management famously stated: "Floods are an act of God, but flood losses are largely an act of man." 30

Still, these early roots of disaster studies created a field that was mainly interested in the aftermath of disaster and focused on practical knowledge for disaster management. Disasters were seen as an event - as a short rupture of normalcy. In the 1990s, this was famously challenged by the work of Wisner and Blaikie, whose 'At Risk' argued that "although events such as hurricanes, floods, and earthquakes serve as triggers for disasters, disasters themselves originate in social conditions and processes that may be far removed from events themselves." ${ }^{31}$ Anthropologists also developed a keen interest in disasters, often focusing on the bottom-up disaster experience of the 'subaltern,' adding new class, gender, and race perspectives to a field that had long been dominated by affluent white men. ${ }^{32}$ These developments heavily nuanced the long-standing belief in the naturalness of disasters and the emphasis on the effects of disasters that had long dominated the field.

As climate change rose in importance on the political agenda, disaster studies increasingly concerned itself with anthropogenic climate change using the established concepts of vulnerability, resilience, and adaptation. ${ }^{33}$ The UN call for the International Decade for Natural Disaster Reduction (IDNDR) during the 1990s and early 2000s played a part in this. Also very decisive was the 2004 'Reducing Disaster Risk' report by the UNDP. As climate change disproportionally impacted the developing world, the need for resilience and adaptation took center stage. This led to an increased interest in these topics in the social sciences, which trickled down to the field of history - albeit slowly.

Historians were relatively late to become involved. ${ }^{34}$ Of course, individual cataclysms like the Black Death or the Lisbon Earthquake had always been of interest to economic, political, and cultural historians. In many ancient and pre-industrial cultures, the systematic recording and

${ }^{28}$ Quarantelli, 'Disaster Studies.' ${ }^{29}$ Tierney, 'From the Margins to the Mainstream?'

${ }^{30}$ White, 'Human Adjustment to Floods,' 2.

31 Tierney, 'From the Margins to the Mainstream?,' 509.

32 Oliver-Smith, 'Anthropological Research.'

${ }^{33}$ Steinberg, Acts of God; Groh, Kempe \& Mauelshagen, Naturkatastrophen; JakubowskiTiessen \& Lehmann, Um Himmels Willen.

${ }^{34}$ Steinberg, Acts of God; Groh, Kempe \& Mauelshagen, Naturkatastrophen; JakubowskiTiessen \& Lehmann, Um Himmels Willen. 
interpretation of calamitous events even constituted an important part of the 'profession' of historians. In imperial China for instance, the official history of each dynasty included a subsection labeled 'the Five Phases' or 'Five Elements,' listing weather anomalies and disasters from floods via locusts to the appearance of dragons. ${ }^{35}$ Dismissed as part of a 'positivist,' descriptive tradition, post-World War II historiography originally paid little attention to disastrous events, with some notable exceptions. In the 1970 s mounting environmental concerns guided some historians to question more systematically the historical interaction between humans and nature, including the many moments when this interaction turned violent. For environmental history, as the new discipline was labeled in the United States, 'natural disasters' were an important subject from the very beginning. The ground-breaking work of Donald Worster on the American Dust Bowl, for instance, was one of the first studies to highlight the historical intertwinement of environment and economy, by showing how capitalist policies led to an aggressive exploitation of the Great Plains, paving the way for disaster. ${ }^{36}$ In their attention to specific kinds of natural hazards and disasters, environmental historians often show 'national' preoccupations in line with the 'primary trauma' of their region: while environmental historians of the Low Countries automatically concentrated on water and floods, German historians were focusing on 'wood shortage' and the decline of forests, 'Waldsterben.' For most nonEuropean historians, the primary trauma was colonization, and both in Latin America and in India, a lot of historical literature on disasters aimed to reveal the 'colonial roots. ${ }^{37}$

Historical climatology also paid ample attention to disasters induced by extreme weather conditions and/or climatic variability. However, while climate history today is very much concerned with the 'impact' of climate on society, ${ }^{38}$ not all pioneers in the field initially were convinced of an intimate climate-society nexus. In the 1960s Emmanuel Le Roy Ladurie still considered climate history "history without human beings." ${ }^{39}$ In his 1971 Times of Feast, Times of Famine he hence concluded that "in the long term the human consequences of climate seem to be slight, perhaps negligible, and certainly difficult to detect." A similar tone was later taken by Jan de Vries, who suggested that "short-term climatic crises stand in relation to economic history as bank robberies to the history of

${ }^{35}$ Brook, The Troubled Empire, 52. $\quad{ }^{36}$ Worster, Dust Bowl.

${ }^{37}$ Radkau, Nature and Power, 10. For the association with colonialism, see for instance Oliver-Smith, 'Peru's Five-Hundred-Year Earthquake.'

${ }^{38}$ Mauelshagen, 'Redefining Historical Climatology.'

${ }^{39}$ Le Roy Ladurie, Histoire du climat; Le Roy Ladurie, Times of Feast. See also Mauelshagen \& Pfister, 'Vom Klima zur Gesellschaft.' 
banking. ${ }^{" 40}$ In contrast to Le Roy Ladurie, British climatologists Gordon Manley and Hubert Lamb made greater allowance for the influence of climate on human cultures, while being critical of the problems that characterized earlier determinist writings. ${ }^{41}$ The work of Lamb and other researchers at the Climatic Research Unit (CRU) saw the formalization of historical climatology into a discipline that addressed "climate reconstruction, the identification and measurement of impact, and adaptation and perception." ${ }^{42}$ During the 1980s, however, the emphasis of the research at the CRU would shift from climate impact to statistical climatology and climate modeling.

Only in the last couple of decades has historical climatology once again placed the climate-society nexus at the center of its work, with Christian Pfister - one of the few historians to contribute to both climate reconstruction and climate impact studies - identifying the vulnerability of past societies to climatic variation as a new focus for historical climatology in $2010 .{ }^{43}$ During the past few years, climate history has boomed as never before. Periods of extreme 'climate stress' - pronounced stretches of extreme weather, or even shifts in the global climate system - are increasingly singled out as 'historical drivers' of major societal changes. Climate histories have been written for regions and societies outside of the traditional hotbed of central and western Europe, while increasing numbers of high-profile studies written by economic, social, and political historians have appeared on the environmental drivers of the decline of the Roman Empire, dynastic changes in Imperial China, or the spread of the Black Death in the fourteenth century. ${ }^{44}$

Apart from climate history, there is yet another historical subdiscipline which traditionally paid great attention to crisis and disaster. For socioeconomic historians, rising grain prices, food shortages, and famine have been a long-standing topic of interest. ${ }^{45}$ The recurrence of 'subsistence crises' - as they were labeled by Meuvret - was considered an intrinsic feature of any pre-twentieth-century economy which only industrialization and the modernization of agricultural production could overcome. ${ }^{46}$ Indeed, famine had always been high on the research agenda of economic historians, though it was a development economist, Amartya Sen, who

${ }^{40}$ De Vries, 'Measuring the Impact of Climate on History,' 603.

${ }^{41}$ Manley, Climate and the British Scene; Lamb, Climate: Past, Present and Future; Lamb, Climate, History.

${ }^{42}$ Ingram, Underhill \& Wigley, 'Historical Climatology'; Wigley, Ingram \& Farmer, Climate and History; Rotberg \& Rabb, Climate and History.

${ }^{43}$ Pfister, 'The Vulnerability of Past Societies.'

${ }^{44}$ Harper, The Fate of Rome; Parker, The Global Crisis; Campbell, The Great Transition.

${ }^{45}$ To cite but one example: Beveridge, 'Wheat Prices and Rainfall' was published in 1922.

${ }^{46}$ Meuvret, 'Les oscillations des prix.' 
forcefully demonstrated the potential of historical famines - in his case the 1943 Bengal Famine - to improve our understanding of present-day hunger. Sen's interpretation of famine as allocation or entitlement crises sparked a renewed interest in historical famines, lasting until today. ${ }^{47}$ Epidemics - and especially the Black Death - and their economic consequences have also received a lot of attention, again often linked to the history of prices and wages. Whether the strong demographic contraction after the Black Death and the changing land-labor ratio led to a 'Golden Age of Labour' has been part of a historiographical debate ever since the nineteenth century (the term itself was coined in 1884), referring to the spike in wages and drop in prices observed by the first price and wage data collectors. ${ }^{48}$ Debates on the same issue continue today. ${ }^{49}$ The consequences of the Black Death not only inspired economic historians, but also attracted attention to cultural aspects, such as its impact on religion, the scapegoating of vulnerable groups, and the evolution of medical thinking. ${ }^{50}$

Moreover, we should keep in mind that the study of past disasters is not the fief of historians alone. In recent years archaeologists, anthropologists, geographers, and climate scientists have all enthusiastically embraced the potential of 'natural archives' - from sediments to ice cores - to reconstruct, date, and interpret the role of both extreme events and long-term changes in the rise and decline of communities, societies, and empires in the past. It has been argued, for instance, that the giant Laacher See volcanic eruption (in the Eifel region between Bonn and Koblenz) 13,000 years ago might explain the sudden disintegration of the homogeneous 'Federmesser' culture of hunter-gatherer communities in many parts of Northern and Western Europe. ${ }^{51}$ In similar ways, a large volcanic eruption in March $536 \mathrm{AD}$ is now thought to be responsible for disrupting climatic conditions, setting the scene for the outbreak of the Justinianic plague, ravaging the Byzantine Empire, and marking the beginning of a 'Late Antique Little Ice Age.' 52

But perhaps the potential of disaster history might be situated not so much in formulating or rebutting this kind of grand narrative on the rise and fall of civilizations, but rather in revealing the causal mechanisms

${ }^{47}$ Sen, Poverty and Famines; Appleby, 'Grain Prices'; Ó Gráda \& Chevet, 'Famine and Market'; Vanhaute \& Lambrecht, 'Famine.'

${ }^{48}$ Rodgers, Six Centuries, 326.

${ }^{49}$ For an overview: Hatcher, 'Unreal Wages'; Hatcher \& Bailey, Modelling the Middle Ages.

${ }^{50}$ Herlihy, The Black Death; Cohn, The Black Death Transformed; Cohn, Cultures of Plague; Cohn, Epidemics.

${ }^{51}$ Riede et al., 'A Laacher See-Eruption Supplement'; Riede, 'Towards a Science of Past Disasters.'

52 Büntgen et al., 'Cooling and Societal Change.' 
which explain why particular disasters did so much harm in some contexts and were countered in others. Over the past decade, this approach has been refined and tested by a group of historians in the Low Countries, including the authors of the present volume. For a wide array of hazards and disasters, from floods to epidemics and epizootics, from famine to sand drifts, the often highly contrasting regional experiences have been analyzed in depth. Such a comparative approach allowed us to question the relative impact of natural variability and exogenous shocks, but also of different coordination systems, state interventions, solidarity mechanisms, economic inequality, and so on. Understanding the changes in landuse which made a region vulnerable to devastating sand drifts $^{53}$, the marginalization processes which exposed certain regions or households to flood risk, ${ }^{54}$ or the different recovery rates of cities after epidemics ${ }^{55}$ turns disaster history into a useful empirical 'laboratory' to improve our knowledge of disasters in the past, ${ }^{56}$ and, at the same time, sheds new light on the functioning of past societies. ${ }^{57}$

\subsection{Interpretative Frameworks in Historical Research}

Long before the history of disasters and its vocabulary of risk, vulnerability, resilience, and adaptation became fashionable, historians investigated major societal 'shocks' and developed interpretations on how to explain the origins and impact of these shocks, and regional variations in their frequency or intensity. From a cultural angle, for example, the inflexibility of cultural practices has been presented as one of the explanations for the failure of some societies to adapt to changing ecological circumstances. ${ }^{58}$ Another line of thought has identified the nature of political regimes democratic or dictatorial - and the accompanying 'inclusive' or 'extractive' institutions as the main determinants of success or failure. ${ }^{59}$ While we acknowledge the importance of these approaches in cultural and political history, and will use them throughout the book, we will expand here on those developed within economic and social history, where perhaps the earliest attempts were made to arrive at overarching interpretations, which often hold direct relevance to the issues of vulnerability and resilience to hazards and shocks. In these fields, a number of interpretative schemes, theories, or models have emerged, aiming to explain not only economic

\footnotetext{
53 De Keyzer \& Bateman, 'Late Holocene Landscape Instability.'

${ }^{54}$ Soens, 'Resilient Societies.'

55 Curtis, 'Was Plague an Exclusively Urban Phenomenon?'

56 Van Bavel \& Curtis, 'Better Understanding Disasters.'

57 Curtis, van Bavel \& Soens, 'History and the Social Sciences.'

58 Krüger et al., Cultures and Disasters. ${ }^{59}$ Acemoglu \& Robinson, Why Nations Fail.
} 
growth and prosperity, but also the opposite: crisis and collapse. In particular, these approaches have been applied and tested on the Black Death, which may have killed half or more of the populations that it affected in Eurasia and parts of Africa in the middle of the fourteenth century. Over the past century, debates on the causes and consequences of the 'latemedieval crisis' and its possible connection to the Black Death have been structured along the lines of four major explanatory frameworks, which still influence, albeit often implicitly, the thinking about hazards and disasters in history more generally. ${ }^{60}$ These frameworks center respectively around (i) population and resources, (ii) the social distribution of power and property, (iii) commercialization and markets, and (iv) institutions.

The first framework is often termed a 'Malthusian' approach, whereby hazards and shocks are the 'positive checks' that stem from the pressure between growing populations in a world with finite resources (Figure 1.2). These increased populations become faced with increasing food prices and rents, while labor at the same time becomes cheaper - thus real income declines. Either populations adapt to these conditions (by reducing the birth rate and hence population growth), forming a preventive check, or they face malnutrition and become vulnerable to epidemic diseases, which forms the positive check that adjusts populations to the available resources. For Sir Michael Postan, for example, the tension between population and resources was at the heart of the so-called late-medieval crisis. In famine analysis, this is translated into the tension between the availability of food and the population which needs to be fed. As long as the productivity of land remained inherently limited, the periodic recurrence of food shortage was seemingly inevitable. Examples of these limitations, with all the associated vulnerabilities, are found not only in thirteenth-century Europe. LateImperial China is also mentioned as a classic example of a technological-environmental 'lock-in,' where the perfection of available technologies and knowledge had pushed the productivity of the soil (and hence population density) far beyond what was 'sustainable,' necessitating ever higher investments to maintain the 'equilibrium' (or postpone the collapse). The inherent tension between population and resources made the region increasingly vulnerable to climatic variability, and led to hazards such as floods and harvest failures. ${ }^{61}$

That is not to say that every climate-centered analysis of disaster accords with a Malthusian framework. For medieval historians like

${ }^{60}$ Hatcher \& Bailey, Modelling the Middle Ages, resumes the debate and its development. Literature on the different approaches framing the Black Death is extensive, see Campbell, The Great Transition, for the most recent synthesis.

${ }^{61}$ Elvin, The Retreat of the Elephants, esp. Chapter 1; Elvin, 'Three Thousand Years of Unsustainable Growth.' 


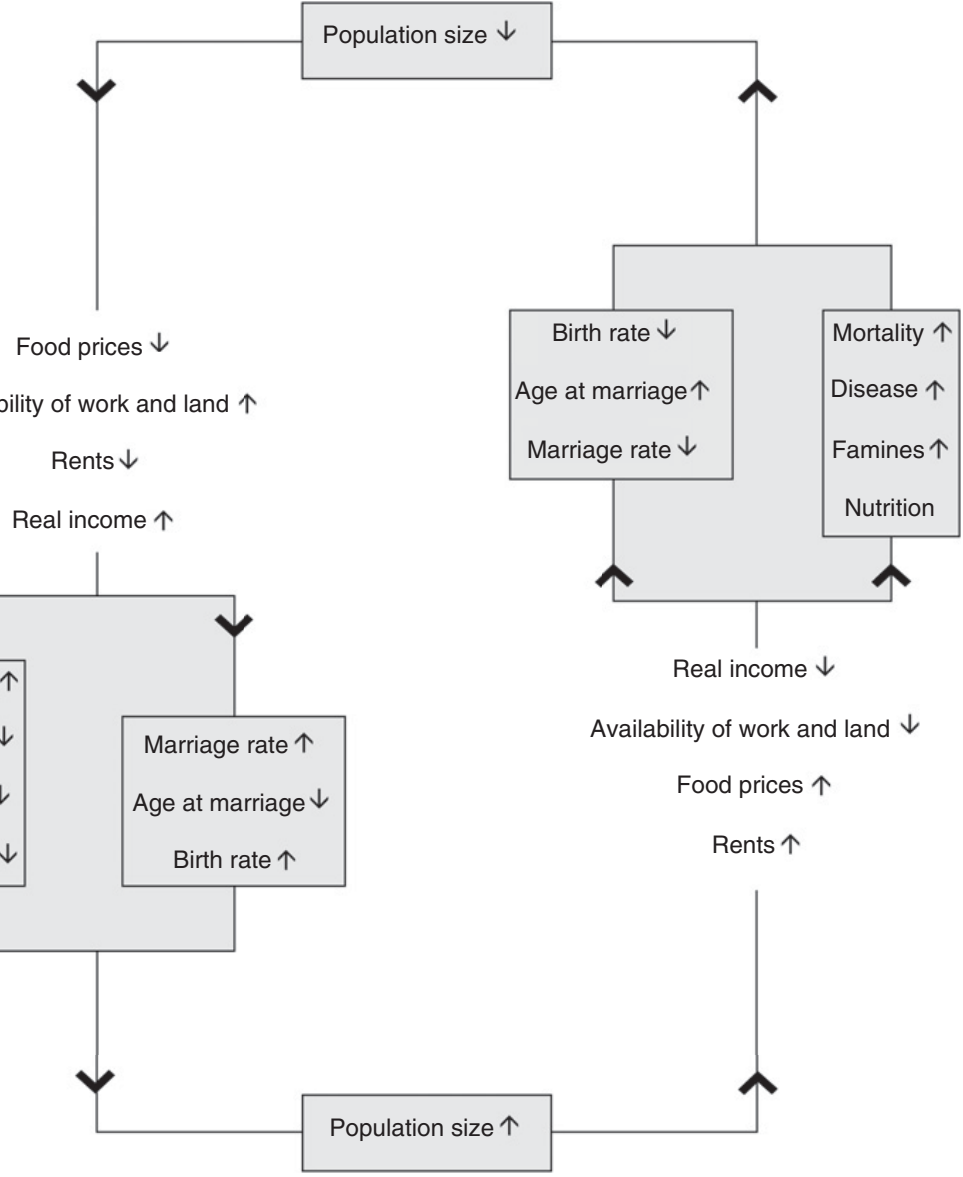

Figure 1.2 The basic Malthusian model, based on the model of John Hatcher and Mark Bailey. Hatcher and Bailey, Modelling the Middle Ages.

Bruce Campbell and David Herlihy, the thirteenth century "status quo of a maximum population subsisting with minimum living standards" could have continued almost indefinitely, had it not been brutally disrupted by the climatic and epidemic upheavals of the fourteenth century. ${ }^{62}$ Put simply, climate- and epidemic-related shocks can also be seen as entirely

${ }^{62}$ Campbell, 'Nature as Historical Protagonist,' 287-288; quoting Herlihy, The Black Death, 38. 
'exogenous' to the people-resources framework rather than having any causal relationship to it.

The main challenge to Malthusian interpretations of the late-medieval crisis, however, was offered by the Marxist analyses of class struggle and the allocation of the means of production between different groups in society. In this second approach, crises did not occur through a lack of resources, but instead because the political economy prevented social groups getting enough access to food or resources. As E. A. Kosminsky stated in 1956 on the late-medieval population crisis in England: "Probably, even given the level of productive forces then prevailing, England could easily have supported a much larger population, if the feudal lords, the feudal church and the feudal state had not sucked the labouring classes dry."63 Depending on the historical context, the 'bad guys' were rent-extracting feudal lords or urban elite governments, profit-seeking factory owners, or 'enlightened' state officials seeking to rationalize economic production, even if we see cases of tenant-on-tenant extortion within the peasantry too. ${ }^{64}$ In Marxist studies, economic crises are an inevitable consequence of elite extraction, but so too are environmental crises. For example, in the 1840s, when Friedrich Engels walked through the streets of Manchester - the 'shock city' of the First Industrial Revolution - he was appalled not only by "the barbarous exploitation of the workers," but also by the "foul air" in the streets and in the cottonand flax-spinning mills where fibrous dust caused "blood-spitting, hard, noisy breathing, pains in the chest, coughs, sleeplessness," the lack of cleanliness and comfort in the houses, and the "narrow, coal-black foulsmelling" River Irk. ${ }^{65}$ What Engels described was the unfolding of a 'slow disaster' - the gradual deterioration of living conditions which put people at risk of early death through chronic illnesses, and made them vulnerable to 'fast disasters,' which in the industrializing cities of the nineteenth century took the form of cholera and tuberculosis epidemics, toxic leaks, and mining catastrophes. ${ }^{66}$ Some of these deteriorating urban conditions even predated the Industrial Revolution - becoming more of a problem through proletarianization and migration in the early-modern period. ${ }^{67}$

The rural counterpart of this approach is found in the long tradition in peasant history of investigating processes of land grabbing, expropriation, and the privatization of formerly common resources and the way they

\footnotetext{
${ }^{63}$ Kosminsky, Studies in the Agrarian History of England.

${ }^{64}$ For this nuanced view: Campbell, 'The Agrarian Problem.'

65 Engels, The Condition of the Working Class; quotations by Clark \& Foster, 'The Environmental Conditions of the Working Class.'

66 Platt, Shock Cities. ${ }^{67}$ Van Oosten, 'The Dutch Great Stink.'
} 
eroded the sustainability of the peasants' livelihoods. For Ramachandra Guha, the clash between the shifting forest cultivation - jhum - practiced by peasant communities in the Northeast of India and the commercial forestry advocated by the British Imperial Forestry department was not only a clash between fundamentally opposed ideas on how to use forest resources, but also a "struggle for existence" between villagers and the Forest Department, and between subsistence and the market. The progressive erosion of the jhum turned many villagers into landless laborers said to be more vulnerable than before. ${ }^{68}$ Since Immanuel Wallerstein's work on economic world-systems, conflicting social relations are no longer situated solely between different classes within society, but also between regions at the core and periphery of the gradually emerging capitalist world-economy. ${ }^{69}$ The shifting frontiers of the worldeconomy are often thought to have been particularly vulnerable to disasters, as the never-ending search for cheap labor and cheap natural resources often abruptly and radically transformed localized societies and environments, leading to over-exploitation of land and resources, and massive delocalization of people. ${ }^{70}$ Recently, Marxist historians have developed an even more environmental approach by focusing on the 'metabolic rift,' a concept introduced by Karl Marx. In this literature, a capitalist mode of production, with a focus on relentless economic growth and strict division of labor, inevitably leads to environmental problems, that may result in true disasters. At the heart is a societal blueprint creating social vulnerabilities such as inequality, precariousness, weak entitlements, and monoculture, which exacerbate the effects of hazards and shocks. ${ }^{71}$

A third main approach to understanding crises and disasters, and their prevention or mitigation, is market dynamics - also labeled the Smithian or modernization approach. This framework focuses on economic growth through commercialization and markets, whereby expanding markets gave producers incentives to specialize, and the growing division of labor allowed economies of scale and productivity gains. These productivity gains in turn allowed living standards to grow in parallel with population, in contrast to Malthusian predictions, potentially postponing or even preventing crisis. ${ }^{72}$ Furthermore, productivity growth offered

${ }^{68}$ Guha, The Unquiet Woods; Guha \& Gadgil, 'State Forestry and Social Conflict.'

${ }^{69}$ Wallerstein, The Modern World-System I.

${ }^{70}$ Moore, 'The Capitalocene.' See Section 7.1.2.

${ }^{71}$ Foster, 'Marx's Theory of Metabolic Rift'; Moore, 'Environmental Crises and the Metabolic Rift.'

${ }^{72}$ For medieval Europe, see for instance Britnell, The Commercialisation of English Society. See also Section 6.1.3. 
surpluses that could be reinvested to reduce pollution or develop protective technologies. Similar arguments have been extended to factor markets: clearly delimited and legally sanctioned private property rights, backed up by the enforcing powers of the state, have been judged by some to stimulate economic development and reduce exposure to disasters.

Of course, there is a reverse side to this kind of explanatory framework since many of these developments such as commercialization and market orientation also gave rise to knock-on developments such as social polarization, proletarianization, inequality, displacement, and so on - essential features guiding heightened vulnerability that have been discussed in the above-mentioned property-rights approach. Put simply, surpluses may have been produced, but in whose hands did they fall? Many of the investments in production often came hand-in-hand with restrictive regulations - forcing producers to cultivate certain types of crop or enter into inequitable credit agreements leading to debt bondage. ${ }^{73}$ While markets could mitigate food shortages, they could also lead to speculation and hoarding - thus conversely making shocks such as harvest failures more severe. ${ }^{74}$ Accordingly, whether market expansion, economic growth, and 'modern' clear property rights increased vulnerability to shocks, or whether they were the key behind an 'escape from disaster,' is a much debated subject which is explicitly dealt with elsewhere in this volume. ${ }^{75}$

In this context it is important to note that markets differ widely in their institutional organization, and this leads us to the fourth main approach to explaining crises and disasters, which focuses on the rules of human interaction: the institutions. Over the past decade, many innovative contributions to this issue, both in economics and in economic history, have been situated in the field of (New)-Institutional Economics. Institutional approaches often focus on the role of property rights and on the role of the state as third-party enforcer of clear and secure property rights, offering stability and stimuli for investment and potentially enhancing the resilience of societies to shocks and disasters ${ }^{76}$ The state, however, may also be part of the problem instead of its solution: when rulers or governments extract part of the productive surplus for their own profit, or allow privileged groups in society to do so, they may constrain the potential for growth and increase vulnerability. ${ }^{77}$ Also, even though institutional approaches often tend to highlight private property rights, alternative property regimes have also been considered. The recognition of the

\footnotetext{
${ }^{73}$ Van Bavel, The Invisible Hand?, 114-119. ${ }^{74}$ Galloway, 'Basic Patterns,' 277.

75 See Sections 7.2.2 and 7.2.3.

76 See the important works by Douglass North in particular.

77 Acemoglu \& Robinson, Why Nations Fail, esp. Chapter 5.
} 
importance of common property regimes in managing hazards and avoiding disasters has increased significantly over the past decades, not least thanks to the work of Elinor Ostrom, who argued that well-managed and well-delimited commons could well prevent a presumably inevitable Tragedy of the Commons. ${ }^{78}$

Institutional arrangements might be the key to understand why the same hazard turned into a full-blown disaster in one case, but not in others. The differential impact of the Black Death is once again a case in point. Comparing the opposing outcomes of the plague in Egypt and England, Stuart Borsch has argued that the causes of Egypt's economic decline, as opposed to England's recovery, are to be found in two contrasting systems of landholding. Whereas English landlords, holding their land as hereditary fiefs, were usually closely involved in the management of their estates and sufficiently interested in reviving their profitability in the changed post-Plague world to bargain with peasants and tenants, the short-term and non-hereditary landholding structure in Egypt stimulated a different attitude. Mamluk and amir landholders were not in direct contact with the peasants on their scattered estates but relied on an extensive bureaucracy supplemented by collective military expeditions in cases of social unrest. Those mechanisms, however, no longer functioned after the Plague as they had done earlier, since labor became scarce and intra-elite coherence crumbled. Vital irrigation systems were no longer maintained, agrarian productivity plummeted and rural depopulation set in. ${ }^{79}$ The comparison between Egypt and England illustrates a general point this book wants to make: when analyzing and explaining how, and whether, hazards turn into disasters, we should not limit the analysis to institutional arrangements directly related to the governance of a particular hazard, but should include the whole arrangement of economy and society.

78 Ostrom, Governing the Commons; De Moor, The Dilemma of the Commoners. See section 4.3.2.

79 Borsch, The Black Death in Egypt and England, 26-27, 32-33, 40-41, 55-56. 